\title{
Fungivorous beetles in basidiocarps of Fomes fomentarius respond differently to microhabitat variables
}

\author{
BJøRn ARNE RUKKE* \\ Division of Zoology, Department of Biology, University of Oslo, P.O. Box 1050 Blindern, N-0316 Oslo, Norway \\ e-mail: bjorn.arne.rukke@forsvarsbygg.no
}

Key words. Fungivorous beetles, Fomes fomentarius, habitat preferences, microhabitat variables, heterogeneous resource, spatial scale, conservation

\begin{abstract}
This study investigates the influence of microhabitat on the presence of several species of fungivorous beetles in basidiocarps of Fomes fomentarius (L.) Kickx. All dead basidiocarps of $F$. fomentarius from fragments of forest in an agricultural landscape in Norway were sampled and dissected, and their content of Cis jacquemarti Mellié, 1848/C. alter (Silvferberg, 1991) (did not distinguish between individuals of these two species), C. bidentatus (Olivier, 1790), C. lineatocribratus Mellié, 1848, Ennearthron cornutum (Gyllenhal, 1827) (Ciidae) and Dorcatoma dresdensis Herbst, 1792 (Anobiidae) were identified. Multiple logistic regression models revealed that these species responded differently to the microhabitat variables. The incidence of these beetles was associated with the size (volume), position (height above ground) and moisture content of the basidiocarps. The analyses also indicated possible interspecific interactions between some of the beetles. The presence of some of the species mainly in basidiocarps at particular stages of degradation indicates a successional pattern of occurrence of these species. Together these results indicate that basidiocarps of $F$. fomentarius are a heterogeneous resource for fungivorous beetles. This has implications for conservation: To preserve the diversity of fungivores, sufficient dead wood has to be left in forests to assure an adequate supply of $F$. fomentarius basidiocarps of different quality.
\end{abstract}

\section{INTRODUCTION}

Many species live in patchily distributed habitats, and these environmental discontinuities affect the distribution of organisms (Wiens, 1976). At larger scales, landscape variables like isolation and habitat size may strongly affect species occurrence (e.g. Kindvall \& Ahlén, 1992), while more locally, microhabitat conditions may determine their spatial distribution (e.g. Midtgaard et al., 1998). Therefore, a multiple scale approach to habitat requirements is more likely to increase our knowledge of species distribution than a single-scale approach.

Both landscape and microhabitat variables affect the occurrence of beetles in basidiocarps of fungi growing on dead wood. The basidiocarp habitat is an example of a spatial hierarchy with more or less clearly defined patches at several nested scales. Basidiocarps are nested within trees, trees within groups of trees and groups of trees within forests. Incidence studies (Rukke \& Midtgaard, 1998; Sverdrup-Thygeson \& Midtgaard, 1998), a markrecapture study (Nilsson, 1997) and a genetic survey (Knutsen et al., 2000) have revealed effects of the largescale variables isolation and habitat size on the population dynamics of Bolitophagus reticulatus (Linnaeus, 1767) (Tenebrionidae), which is monophagous on basidiocarps of Fomes fomentarius (L.) Kickx. Another large-scale study showed that several other species inhabiting basidiocarps of $F$. fomentarius are also affected by changes in degree of habitat isolation and habitat size. Like B. reticulatus, the incidence of Cis jacquemarti Mel- lié, 1848/C. alter (Silvferberg, 1991) (individuals of these two species were not distinguished), $C$. bidentatus (Olivier, 1790), C. lineatocribratus Mellié, 1848, Ennearthron cornutum (Gyllenhal, 1827) (Ciidae) and Dorcatoma dresdensis Herbst, 1792 (Anobiidae) decreases with increased habitat isolation and reduced habitat size (Rukke, 2000 - in this paper C. alter $=C$. nitidius (Fabricius, 1792)). Additionally, an incidence study at a lower scale has shown the effect of several microhabitat variables on the presence of $B$. reticulatus in basidiocarps (Midtgaard et al., 1998).

Since dead wood and its associated fungi are greatly reduced in quantity in today's forests due to forestry practices (Haila et al., 1994; Bader et al., 1995; Esseen et al., 1997), information on the habitat requirements of the beetles associated with such habitats is particularly interesting for conservation purposes. To prevent habitat depletion and subsequent population decline, a better knowledge of a species' habitat requirements, at all relevant scales, is required.

The present study aims to add information about smallscale habitat requirements of beetles associated with fungi living on dead wood. The effects of several microhabitat variables on the presence of $C$. jacquemarti/C. alter, $C$. bidentatus, $C$. lineatocribratus, $E$. cornutum and $D$. dresdensis in the basidiocarps of $F$. fomentarius were investigated in an attempt to reveal whether the species have particular habitat preferences.

\footnotetext{
* Current address: Kranveien 4, 0684 Oslo, Norway
} 
TABLE 1. Species of Coleoptera found in the dead basidiocarps of Fomes fomentarius $(\mathrm{n}=587)$ from the study area. Included are number of specimens $(\mathrm{S})$ and number of occurrences $(\mathrm{O})$.

\begin{tabular}{llrrlll}
\hline Species & Family & $\mathrm{S}$ & $\mathrm{O}$ & Species & Family & $\mathrm{S}$ \\
\hline Cis jacquemarti/alter & Ciidae & 6783 & 386 & Phyllotreta striolata & Chrysomelidae & 1 \\
Bolitophagus reticulatus & Tenebrionidae & 2153 & 134 & Phyllotreta undulata & Chrysomelidae & 1 \\
Dorcatoma dresdensis & Anobiidae & 181 & 40 & Atomaria fuscata & Cryptophagidae & 1 \\
Cis bidentatus & Ciidae & 168 & 46 & Atomaria impressa & Cryptophagidae & 1 \\
Ennearthron cornutum & Ciidae & 122 & 55 & Dalopius marginatus & Elateridae & 1 \\
Cis lineatocribratus & Ciidae & 110 & 32 & Selatosomus aeneus & Elateridae & 1 \\
Cis quadridens & Ciidae & 58 & 7 & Liestes seminigra & Endomychidae & 1 \\
Ropalodontus perforatus & Ciidae & 20 & 3 & Xylophilus corticalis & Eucnemidae & 1 \\
Leptusa fumida & Staphylinidae & 12 & 9 & Cyphon sp. & Helodidae & 1 \\
Rhizophagus dispar & Rhizophagidae & 9 & 8 & Agathidium badium & Leiodidae & 1 \\
Leptusa pulchella & Staphylinidae & 6 & 6 & Malachius bipustulatus & Malachiidae & 1 \\
Acrulia inflata & Staphylinidae & 5 & 4 & Rhizophagus bipustulatus & Rhizophagidae & 1 \\
Dinaraea aequata & Staphylinidae & 3 & 3 & Rhizophagus nitidulus & Rhizophagidae & 1 \\
Dryocoetes alni & Scolytidae & 3 & 2 & Atheta fungi & Staphylinidae & 1 \\
Ennearthron laricinum & Ciidae & 2 & 1 & Atheta nigricornis & Staphylinidae & 1 \\
Agonum micans & Carabidae & 1 & 1 & Gabrius sp. & Staphylinidae & 1 \\
Pterostichus oblongopunctatus & Carabidae & 1 & 1 & Quedius xanthopus & Staphylinidae & 1 \\
Cerylon histeroides & Cerylonidae & 1 & 1 & & 1 \\
\hline & & & & & 1
\end{tabular}

\section{MATERIAL AND METHODS}

The study area consisted of 58 forest patches ("forest islands") in an agricultural area (1585 ha) in the Lier municipality $\left(59^{\circ} 48^{\prime} \mathrm{N}, 10^{\circ} 16^{\prime} \mathrm{E}\right)$, Norway. The size of the forest islands varied from 729 to $63386 \mathrm{~m}^{2}$. Data was collected from April to mid June 1993. In the study area all 587 dead basidiocarps of $F$. fomentarius (as defined by Matthewman \& Pielou (1971) were collected from 185 trees (125 birches (Betula pubescens) and 60 grey alder (Alnus incana)) and dissected to reveal their content of beetles. Boreal deciduous trees were the dominant tree species in the forest islands, and $F$. fomentarius basidiocarps were by far the most common basidiocarps on dead wood in the study area (pers. obs.).

All adult beetles in the basidiocarps were recorded (Table 1). In the identification of the beetles, it was difficult to separate individuals of the species $C$. glabratus Mellié, 1848, C. jacquemarti and $C$. alter because they were desiccated (Sindre Ligaard, pers. comm.). Since C. glabratus is rarely found in basidiocarps of $F$. fomentarius (e.g. Økland, 1995; Fossli \& Andersen, 1998; Jonsell, 1999), all these individuals were treated as an assemblage of the two species C. jacquemarti and $C$. alter, which is abbreviated to C. jacquemarti/alter. Only $C$. jacquemarti/alter and the four species $C$. bidentatus, C. lineatocribratus, $E$. cornutum and $D$. dresdensis were common enough for further analyses (except for $B$. reticulatus, which is treated in Midtgaard et al. (1998)).

These species are found in central Europe (Lucht, 1987) and Scandinavia (Lindroth, 1960; Vik, 1991). They may inhabit several species of dead wood fungi (Paviour-Smith, 1960; Kaila et al., 1994; Thunes, 1994; Økland, 1995; Fossli \& Andersen, 1998; Jonsell, 1999), but $F$. fomentarius is probably their most important host in the study area as it is the dominant dead wood fungus. Little is known about the life history of the study species, but one generation is probably completed within two years. Therefore, larger dead basidiocarps of $F$. fomentarius, which may persist for several years before disintegrating totally, may support several generations of the beetles. In addition, most trees harbour several basidiocarps, which usually do not die simultaneously, sometimes making a tree bearing basidiocarps a suitable habitat patch for more than a decade.

The basidiocarps in this study were earlier used to study the effect of habitat and landscape variables on the presence of the same beetle species at higher spatial scales, i.e. at the level of individual trees with basidiocarps (the tree level) and the level of forest islands (see Rukke, 2000). At the tree level, both habitat isolation and habitat size were found to influence the presence of each of the beetle species on a tree. To reduce the influence of these tree-related variables in the present study, only basidiocarps from trees having a certain minimum probability of beetle presence were included in the analyses. These probabilities were estimated for each of the beetle species from their respective multiple logistic regression model at the tree level. For C. jacquemarti/alter the criterion was set to $70 \%$, whilst it was set to $50 \%$ for the four other species in order to include a sufficient number of basidiocarps in the analyses. Additionally, all dead basidiocarps from trees having at least one basidiocarp inhabited by the respective species were included. Being able to colonise a tree, a beetle species also has the possibility to inhabit all the other basidiocarps on that tree, and consequently be tested for microhabitat preferences there.

Univariate and forward, stepwise, multiple logistic regressions (enter- and check-back-criteria were $\mathrm{p}<0,05$ and $\mathrm{p}<0,06$ respectively) (see Hosmer \& Lemeshow, 1989) were used to reveal effects of microhabitat variables on the binary response variable presence/absence of each beetle species in the basidiocarps. Presence of a beetle species was defined as at least one adult present in a basidiocarp. Logistic regression is not an appropriate method of analysis if a categorical predictor variable has one or more categories with $100 \%$ presence or absence. Therefore, contingency table analyses were used when a categorical predictor variable had one or more categories with $100 \%$ presence or absence. Spearman-rank correlations were used to reveal correlation between predictor variables on a continuous scale. To investigate the relationships between number of bee- 


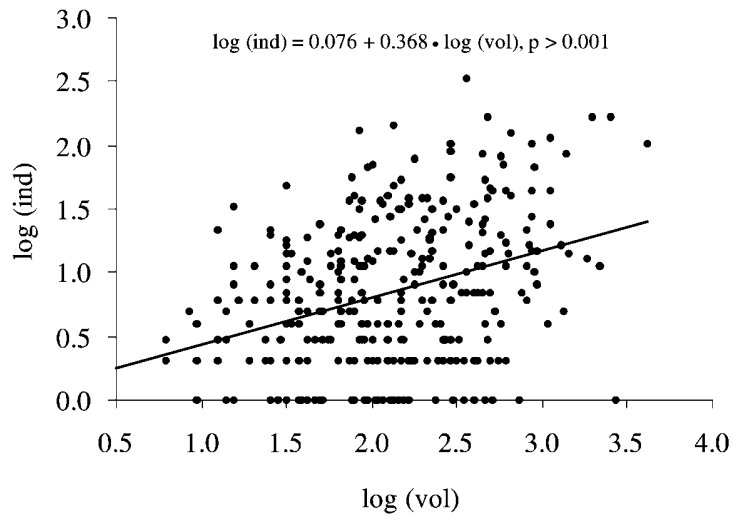

Cis lineatocribratus

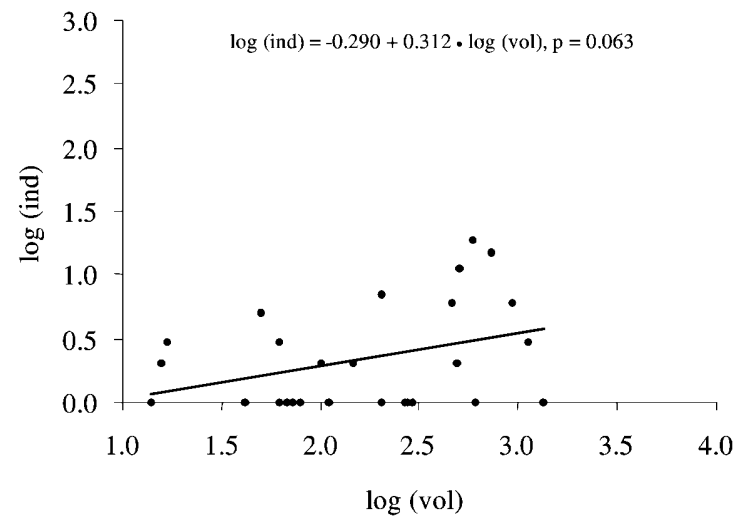

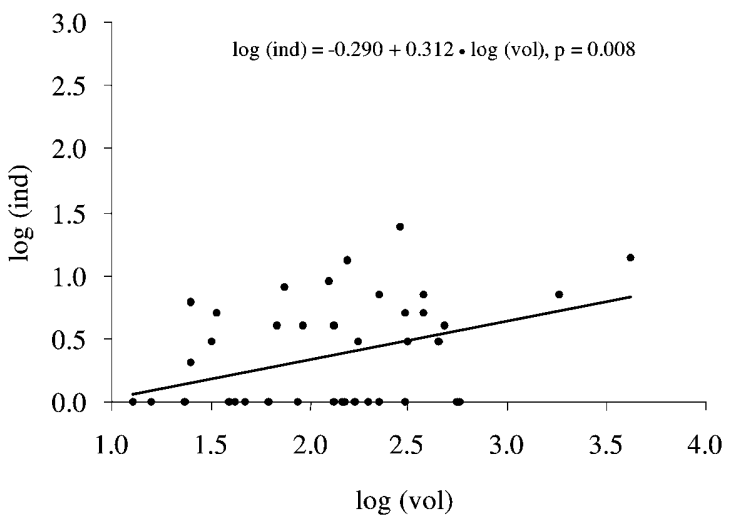

Dorcatoma dresdensis

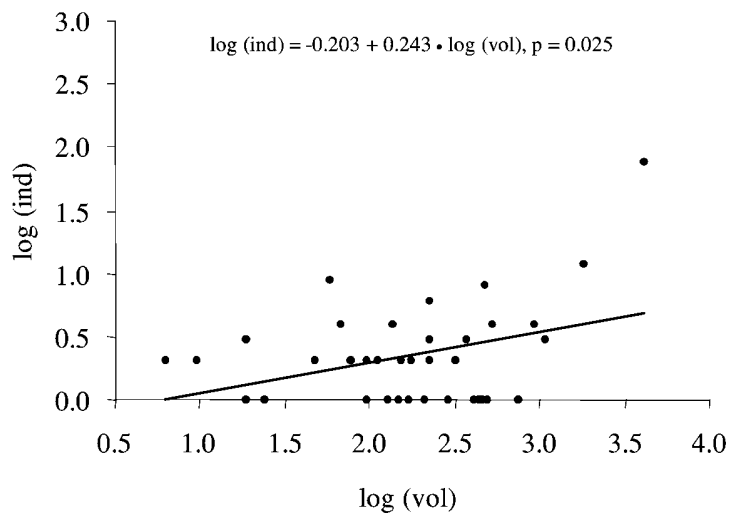

Fig. 1. Linear regressions relating number of individuals of each species to basidiocarp volume of inhabited basidiocarps. Included are the equations of the linear regressions and their p-values.

tles of each species and basidiocarp volume, linear regressions were calculated.

All the variables are described in Table 2. Non-linear relations between some of the variables were found. Therefore, the continuous predictor variables were categorised in the logistic regression analyses (see Hosmer \& Lemeshow, 1989). All analyses were performed using the computer program JMP (SAS Institute Inc., 1997).

\section{RESULTS}

C. jacquemarti/alter was by far the most numerous and frequently found species in the 587 dead $F$. fomentarius basidiocarps sampled. Density of each species was measured as number of individuals per unit volume and weight of basidiocarp in the basidiocarps inhabited by that particular species. The density of $C$. jacquemarti/alter was far higher than that of the other species (Table 3).

Large basidiocarps had more individuals of $C$. jacquemarti/alter, C. bidentatus, C. lineatocribratus and D. dresdensis than small basidiocarps (Fig. 1). There was no such trend for E. cornutum ( $\mathrm{p}>0.50)$

Basidiocarp size also affected the incidence of $C$. jacquemarti/alter and D. dresdensis. Multiple logistic regression models indicate that large basidiocarps were more likely to be inhabited by these beetles than small basidiocarps (Table 4 and Fig. 2).

The presence of some of the beetles was associated with "height above ground". Basidiocarps at the ground level were more likely to be inhabited by $C$. jacquemarti/alter than those above ground level, while the opposite applied to E. cornutum and D. dresdensis (Table 4 and Fig. 2).

The presence of $C$. bidentatus and $C$. lineatocribratus was significantly associated with the moisture content of the basidiocarps (Table 4 and Fig. 2). C. bidentatus occurred more frequently in the driest basidiocarps than in the moister ones. For $C$. lineatocribratus the overall trend was the reverse, i.e. increased presence in the more moist basidiocarps.

The patterns of incidence shown by some of the species were not independent (Table 4). The presence of $C$. jacquemarti/alter and $D$. dresdensis was positively correlated with that of $C$. bidentatus and $E$. cornutum respectively, whilst presence of $D$. dresdensis was negatively associated with that of $B$. reticulatus. In the analysis of the interaction between $C$. lineatocribratus and $C$. bidentatus, logistic regressions could not be applied because the category $\mathrm{C}$. lin[1] had no basidiocarps containing $C$. 

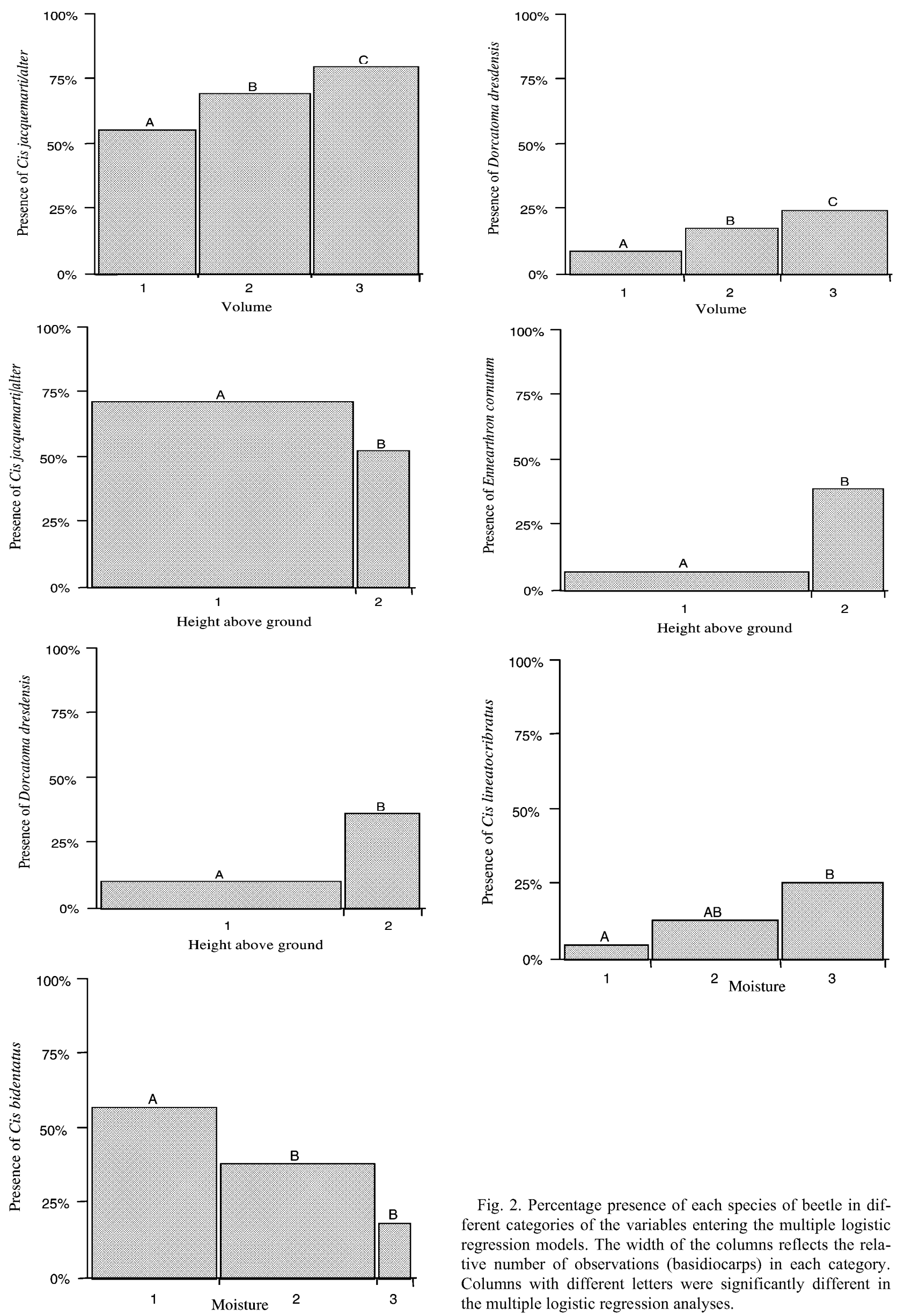

Fig. 2. Percentage presence of each species of beetle in different categories of the variables entering the multiple logistic regression models. The width of the columns reflects the relative number of observations (basidiocarps) in each category. Columns with different letters were significantly different in the multiple logistic regression analyses. 
TABLE 2. Description of predictor variables (Var.) and their values (Value).

\begin{tabular}{|c|c|c|}
\hline Var. & Description & Values \\
\hline B. ret & $\begin{array}{l}\text { Presence vs. absence of Bolitophagus reticulatus. Presence was defined as at } \\
\text { least one beetle being present in a basidiocarp. }\end{array}$ & {$[0]$ : absence, $[1]$ : presence } \\
\hline C. bid & $\begin{array}{l}\text { Presence vs. absence of Cis bidentatus. Presence was defined as at least one } \\
\text { adult beetle being present in a basidiocarp. }\end{array}$ & [0]: absence, [1]: presence \\
\hline C. $\operatorname{lin}$ & $\begin{array}{l}\text { Presence vs. absence of Cis lineatocribratus. Presence was defined as at least } \\
\text { one adult beetle being present in a basidiocarp. }\end{array}$ & {$[0]$ : absence, $[1]$ : presence } \\
\hline C. jac & $\begin{array}{l}\text { Presence vs. absence of Cis jacquemarti/alter. Presence was defined as at least } \\
\text { one adult beetle being present in a basidiocarp. }\end{array}$ & [0]: absence, $[1]$ : presence \\
\hline D. dre & $\begin{array}{l}\text { Presence vs. absence of Dorcatoma dresdensis. Presence was defined as at least } \\
\text { one adult beetle being present in a basidiocarp. }\end{array}$ & {$[0]$ : absence, $[1]$ : presence } \\
\hline Degr & Percentage degradation of a basidiocarp. & {$[1]:<1,[2]: 1-24,[3]: 25-50,[4]:>50$} \\
\hline E. cor & $\begin{array}{l}\text { Presence vs. absence of Ennearthron cormutum. Presence was defined as at least } \\
\text { one adult beetle being present in a basidiocarp. }\end{array}$ & {$[0]$ : absence, $[1]$ : presence } \\
\hline Hag & $\begin{array}{l}\text { The height above ground describes whether a basidiocarp was situated at or } \\
\text { above the ground level. }\end{array}$ & $\begin{array}{l}\text { [1]: at the ground level, } \\
\text { [2]: above the ground level }\end{array}$ \\
\hline Mois & $\begin{array}{l}\text { The moisture of a basidiocarp measured by dividing the weight on collection } \\
\text { day by the weight after drying for } 4 \text { months at } 20^{\circ} \mathrm{C} \text {. }\end{array}$ & $\begin{array}{l}{[1]:<1.50 \text { (Dry), }} \\
{[2]: 1.50-2.50 \text { (Medium dry), }} \\
{[3]:>2.50 \text { (Moist) }}\end{array}$ \\
\hline Vol & $\begin{array}{l}\text { The volume of a basidiocarp in } \mathrm{cm}^{3} \text { estimated by } 1 / 4 \text { volume of an ellipsoid } \\
\left((4 / 3) \times \pi \times r_{1} \times r_{2} \times r_{3}\right) \text {. }\end{array}$ & {$[1]:<75,[2]: 75-200,[3]:>200$} \\
\hline
\end{tabular}

bidentatus. A contingency table analysis showed that $C$. lineatocribratus was present in 19\% (28/150) of the basidiocarps that lacked $C$. bidentatus and in none $(0 / 17)$ where $C$. bidentatus was present (Contingency table analysis: Pearson- $\chi^{2}=3.81, \mathrm{p}=0.05$ ).

The percentage degradation of the basidiocarp (Degr) was not included in the multiple logistic regression models because this characteristic is probably too much modified by the presence of the beetles themselves. In the univariate analyses (Table 5 and Fig. 3) Degr was related to the presence of C. jacquemarti/alter, E. cornutum and D. dresdensis. E. cornutum was more likely to be present in basidiocarps of intermediate $(25-50 \%)$ degradation than in more or less degraded ones (Degr[3] vs. Degr[4] was almost significantly different, $\mathrm{p}=0.09$ ). Incidence of C. jacquemarti/alter was lower in the least degraded basidiocarps compared to other grades. Additionally, no D. dresdensis $(0 / 22)$ was present in the least degraded basidiocarps, while the rest of the basidiocarps roughly had the same presence (Contingency table analysis: Pearson- $\left.\chi^{2}=6.19, \mathrm{p}=0.10\right)$.

Some predictor variables had univariate significant affect on the presence of some study species (Table 5) without entering the multiple regression model of the respective species (Table 4). This was probably because these variables were confounded with others, which entered the models. Notably, for all species moisture content of the basidiocarps decreased with height above ground (Table 6).

\section{DISCUSSION}

This study revealed that microhabitat variables differently affected the presence of beetle species in basidiocarps of $F$. fomentarius. An earlier study, in the same area (Rukke, 2000), showed that habitat variables at higher spatial scales also differently influenced the incidence of the beetle species, while the responses to the landscape variables "increased habitat isolation" and "decreased habitat size" were more uniform and reduced beetle presence on basidiocarp trees. Together the results from these studies at different scales better explain the beetles' spatial distribution than would a single-scale perspective, and argues for a multi-scale approach when studying ecological systems.

\section{Volume of basidiocarps}

This study revealed that basidiocarp size is an important habitat variable for several dead wood fungivores. Incidence of C. jacquemartilalter and $D$. dresdensis was higher in large than in small basidiocarps. In another study Jonsell et al. (1999) found similar results for several beetles, including $C$. jacquemarti, $C$. alter and $D$. dresdensis, and the same trend was also reported for $B$. reticulatus (Midtgaard et al., 1998). There may be several reasons why the number of fungivorous beetles is higher in large compared to small basidiocarps. If large basidiocarps have stronger visual and/or olfactory cues, they may be more easily located by beetles searching for a habitat. Regarding olfactory cues, Jonsell and Nordlander (1995) observed that beetles of the family Ciidae breeding in basidiocarps of Fomitopsis pinicola were strongly attracted to the odour of this fungus. However, in the same study species of the similar ciid guild associated with $F$. fomentarius were not attracted to the fungal odours of $F$. fomentarius. Another explanation relates the increased presence of beetles in large basidiocarps to the prolonged period of possible colonisation and inhabitancy. Compared to small basidiocarps larger ones probably last longer before they are totally degraded, and once colonised there is also more food available for consumption. Finally, size can be important because micro- 

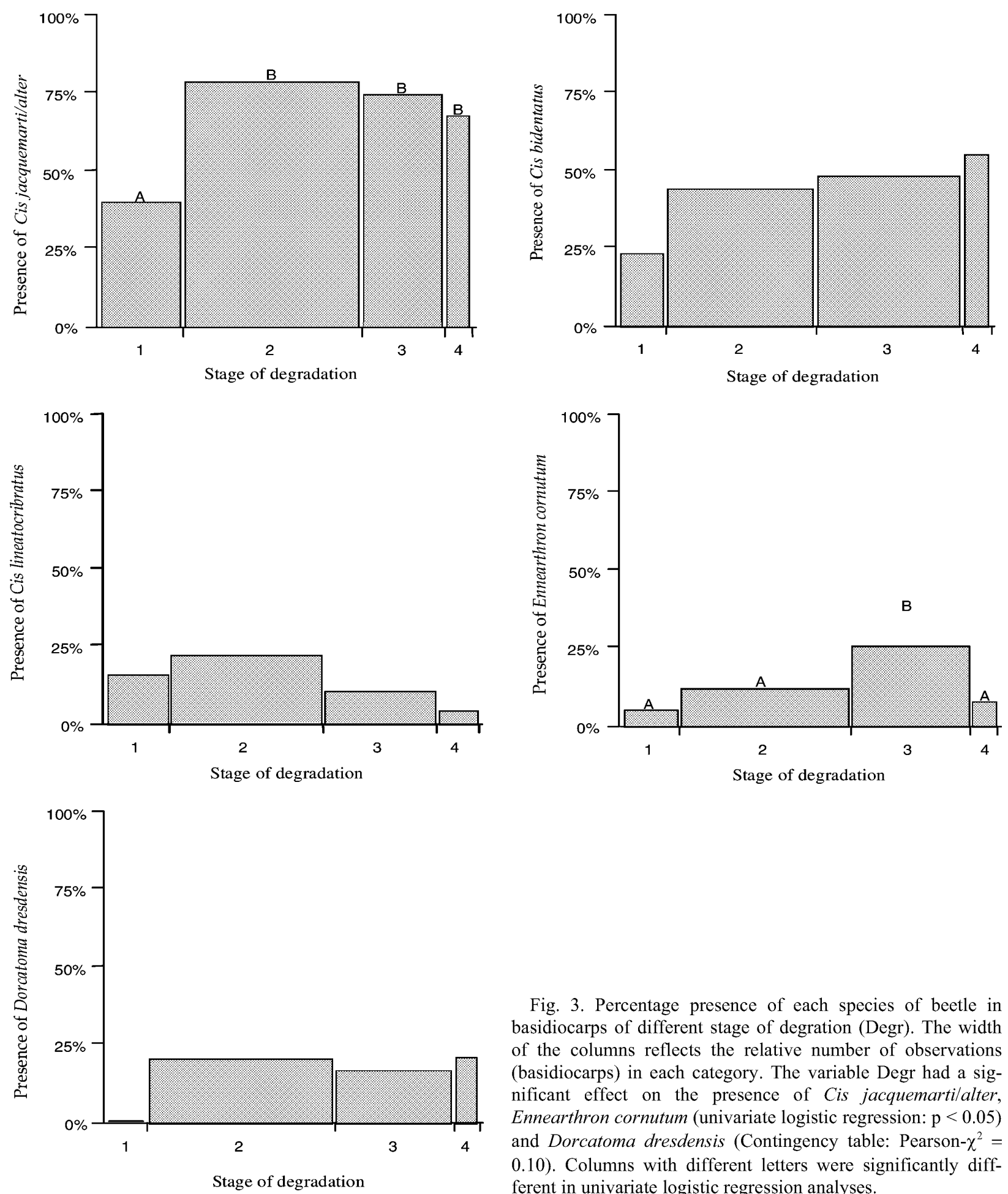

Fig. 3. Percentage presence of each species of beetle in basidiocarps of different stage of degration (Degr). The width of the columns reflects the relative number of observations (basidiocarps) in each category. The variable Degr had a significant effect on the presence of Cis jacquemarti/alter, Ennearthron cornutum (univariate logistic regression: $\mathrm{p}<0.05$ ) and Dorcatoma dresdensis (Contingency table: Pearson- $\chi^{2}=$ 0.10 ). Columns with different letters were significantly diffferent in univariate logistic regression analyses.

climatic conditions may be more stable in larger basidiocarps. In them changes in moisture and temperature are most likely dampened compared to small basidiocarps.

C. jacquemarti/alter, C. bidentatus, C. lineatocribratus and $D$. dresdensis, were more numerous in large basidiocarps. The number of $B$. reticulatus also increases with basidiocarp size (Midtgaard et al., 1998). If individuals from all basidiocarps on a tree constitute a local population of a beetle species (Rukke, 2000), large basidiocarps with their higher number of individuals more substan-

tially contribute to reduce the risk of local population extinction than small basidiocarps. This is because increasing population size generally decreases the risk of stochastic extinction (Williamson, 1981; Diamond, 1984; Soulé, 1986).

There was a variation between species in abundance and density in the basidiocarps. C. jacquemarti/alter had both a higher incidence and density than the other beetles. A dominant position of $C$. jacquemarti and $C$. alter regarding incidence and density among fungivorous bee- 
TABLE 3. Abundance and density of beetles in the basidiocarps. Included is the total number of specimens sampled (No. spec.), number of basidiocarps with presence (No. bas.), percentage of basidiocarps with presence (Perc.) and density measured as average number of specimens per unit volume $\left(\mathrm{cm}^{3}\right)$ in inhabited basidiocarps (No./vol.) and average number of specimens per unit weight $(\mathrm{g})$ in inhabited basidiocarps (No./wei.) for each species.

\begin{tabular}{lccccc}
\hline Species & No. spec. & No. bas. & Perc. & No./vol. & No./wei. \\
\hline $\begin{array}{l}\text { Cis jacque- } \\
\text { marti/alter }\end{array}$ & 6783 & 386 & $66 \%$ & 0.065 & 0.252 \\
$\begin{array}{l}\text { Cis bidenta- } \\
\text { tus }\end{array}$ & 168 & 46 & $8 \%$ & 0.013 & 0.045 \\
$\begin{array}{l}\text { Cis lineato- } \\
\text { cribratus }\end{array}$ & 110 & 32 & $5 \%$ & 0.011 & 0.041 \\
$\begin{array}{l}\text { Ennearthron } \\
\text { cornutum }\end{array}$ & 122 & 55 & $9 \%$ & 0.011 & 0.022 \\
$\begin{array}{l}\text { Dorcatoma } \\
\text { dresdensis }\end{array}$ & 181 & 40 & $7 \%$ & 0.012 & 0.041 \\
\hline
\end{tabular}

tles in basidiocarps of $F$. fomentarius, has also been reported earlier (Fossli \& Andersen, 1998; Jonsell, 1999).

\section{Height above ground}

Position of basidiocarps, at or above ground level, differently affected the presence of $C$. jacquemarti/alter and $E$. cornutum and $D$. dresdensis. This probably reflects that basidiocarps at the ground level are a different kind of habitat from those higher above ground. The former have a higher moisture content (Table 6), and they are probably less exposed to temperature extremes, than basidiocarps above ground level as they are less exposed to sun and may be covered by snow during winter. The incidence of $C$. jacquemarti/alter was highest in basidiocarps at ground level. Other studies confirm both $C$. jacquemarti's and C. alter's preference for ground level basidiocarps (Fossli \& Andersen, 1998; Jonsell et al., 1999). In the present study this preference cannot be attributed to moisture component of this variable since $C$. jacquemartilalter did not show preference for basidiocarps of any moisture level (Table 5).

In contrast to C. jacquemarti/alter, E. cornutum and D. dresdensis were more frequently found in basidiocarps above ground level. Here the moisture content probably influenced the beetles' presence because the moister basidiocarps had reduced presence of both species (Table 5). Additionally, due to less vegetation and absence of snow cover the basidiocarps above ground level probably were more exposed to sun which increased larval development speed. This would promote survival as the period of exposure to predators and parasites/parasitoids is reduced. Accordingly, Fossli \& Andersen (1998) only found $E$. cornutum in basidiocarps in warm microclimates (exposed and southwest facing slopes with dry ground).

Contrary to other studies (Fossli \& Andersen, 1998; Jonsell \& et al., 1999), C. lineatocribratus apparently did not show a significant preference for basidiocarps at ground level. However, this apparent lack of preference probably can be attributed to a low number of above
TABLE 4. Multiple logistic regression models explaining presence/absence of each species of beetle in the basidiocarps. Included is the order (Step) in which the variables (Var) entered into the model. Likelihood ratio test-value $(\mathrm{G})$ and level of significance of a chi square-table ( $p$-value) for each step and the odds ratio (O.R.) and $95 \%$ - confidence interval $(95 \%$-CI) of each variable's categories are also presented. For a given category $(\mathrm{x})$ the odds ratio is given as: odds $(\mathrm{x}) /$ odds $(\mathrm{x}-1)$.

\begin{tabular}{|c|c|c|c|c|c|c|}
\hline Species & Step & Var & G & $\mathrm{p}$-value & O.R. & $95 \%$-CI \\
\hline \multirow{3}{*}{$\begin{array}{l}\text { Cis jac- } \\
\text { quemarti } \\
\text { /alter } \\
(\mathrm{n}=463)\end{array}$} & 1 & Vol[2] & 21.99 & $<0.001$ & 1.79 & $1.11-2.89$ \\
\hline & & Vol[3] & & & 1.89 & $1.10-3.22$ \\
\hline & 2 & $\operatorname{Hag}[2]$ & 10.12 & 0.001 & 0.43 & $0.25-0.72$ \\
\hline \multirow{3}{*}{$\begin{array}{l}\text { Cis biden- } \\
\text { tatus } \\
(\mathrm{n}=92)\end{array}$} & 1 & C. jac [1] & 4.18 & 0.041 & 3.11 & $1.16-8.37$ \\
\hline & 2 & Mois[2] & 7.56 & 0.023 & 0.35 & $0.13-0.92$ \\
\hline & & Mois[3] & & & 0.47 & $0.09-2.59$ \\
\hline \multirow{2}{*}{$\begin{array}{l}\text { Cis linea- } \\
\text { tocribratus } \\
(\mathrm{n}=167)\end{array}$} & 1 & Mois[2] & 8.56 & 0.013 & 2.51 & .70 \\
\hline & & Mois[3] & & & 2.19 & $0.89-5.35$ \\
\hline \multirow{2}{*}{$\begin{array}{l}\text { Ennear- } \\
\text { thron } \\
\text { cornutum } \\
(\mathrm{n}=312)\end{array}$} & 1 & $\operatorname{Hag}[2]$ & 35.49 & $<0.001$ & 6.45 & $3.34-12.45$ \\
\hline & 2 & D. dre[1] & 5.50 & 0.019 & 3.11 & $1.24-7.83$ \\
\hline \multirow{4}{*}{$\begin{array}{l}\text { Dorcatoma } \\
\text { dresdensis } \\
(\mathrm{n}=199)\end{array}$} & 1 & $\operatorname{Hag}[2]$ & 15.09 & $<0.001$ & 6.69 & $2.38-15.79$ \\
\hline & 2 & Vol[2] & 8.50 & 0.014 & 3.58 & $1.19-10.75$ \\
\hline & & Vol[3] & & & 1.64 & $0.66-4.05$ \\
\hline & 3 & B. $\operatorname{ret}[1]$ & 6.88 & 0.009 & 0.28 & $0.10-0.78$ \\
\hline
\end{tabular}

ground basidiocarps (only twelve of the 167 basidiocarps) giving low statistical power to reveal this particular trend.

\section{Moisture of basidiocarps}

The incidence of $B$. reticulatus is reduced in moist compared to dry basidiocarps (Midtgaard et al., 1998). In the present study, $C$. bidentatus had a similar response, whereas $C$. lineatocribratus preferred moister basidiocarps. As mentioned above, E. cornutum and D. dresdensis preferred drier basidiocarps, but this tendency disappeared in the multiple model due to this variable's correlation with height above ground. Some beetle species may prefer dry basidiocarps due to better winter survival in them than in moister basidiocarps. B. reticulatus is freeze-tolerant and freeze-avoidant in dry and moist basidiocarps respectively, and survival is poorer in inoculated frozen than extensively super-cooled specimens (Gehrken et al., 1991). Additionally, when the moisture content in their environment increases, many insects have a reduced tolerance of high temperatures (Harmon et al., 1986). This may promote preference for dry basidiocarps. Another factor possibly contributing to this preference could be an oxygen deficit in soaked basidiocarps, which delimits the biological activity to only the outer parts. The advantages of occupying dry basidiocarps must be outweighed by other factors facilitating $C$. lineatocribratus presence in moister basidiocarps. Since most dead wood fungivores favour dry and somewhat sun-exposed conditions (Jonsell, 1999), one advantage may be reduced 
TABLE 5. Univariate logistic regression models explaining presence / absence of each species of beetle in basidiocarps. Included are the predictor variables' total significance-level (p-value) and each category's percentage of trees with presence (Perc.), odds ratio (O.R.) and $95 \%$-confidence interval $(95 \%-\mathrm{CI})$. For a given category $(\mathrm{x})$ the odds ratio is given as: odds $(\mathrm{x}) /$ odds $(\mathrm{x}-1)$.

Cis jacquemarti/alter $(\mathrm{n}=463)$

\begin{tabular}{lccccc}
\hline Var. & p-value & Cat. & Perc. & O.R. & $95 \%$-CI \\
\hline B. ret & 0.292 & {$[0]$} & 69 & & \\
& & {$[1]$} & 74 & 1.30 & $0.80-2.12$ \\
C. bid & 0.171 & {$[0]$} & 69 & & \\
& & {$[1]$} & 79 & 1.71 & $0.77-3.82$ \\
C lin & 0.168 & {$[0]$} & 69 & &
\end{tabular}

$\begin{array}{llllll}\text { C. } \operatorname{lin} & 0.168 & {[0]} & 69 & & \\ & & {[1]} & 81 & 1.93 & 0.72-5.21\end{array}$

D. dre $\quad 0.109 \quad[0]$

Degr $\quad<0.001 \quad[1]$

$$
\begin{aligned}
& {[1]} \\
& {[1]}
\end{aligned}
$$

$$
69
$$

\begin{tabular}{|c|c|c|c|c|c|}
\hline & & & \\
\hline & & {$[2]$} & 81 & 5.74 & $3.44-9.57$ \\
\hline & & {$[3]$} & 77 & 0.80 & $0.45-1.40$ \\
\hline & & {$[4]$} & 70 & 0.70 & $0.30-1.67$ \\
\hline \multirow[t]{2}{*}{ E. cor } & \multirow[t]{2}{*}{0.505} & {$[0]$} & 70 & & \\
\hline & & {$[1]$} & 75 & 1.30 & $0.59-2.84$ \\
\hline \multirow[t]{2}{*}{ Hag } & \multirow[t]{2}{*}{0.001} & {$[1]$} & 73 & & \\
\hline & & {$[2]$} & 54 & 0.43 & $0.26-0.71$ \\
\hline \multirow[t]{3}{*}{ Mois } & \multirow[t]{3}{*}{0.573} & {$[1]$} & 64 & & \\
\hline & & {$[2]$} & 70 & 1.20 & $0.71-2.00$ \\
\hline & & {$[3]$} & 72 & 1.30 & $0.71-1.79$ \\
\hline \multirow[t]{3}{*}{ Vol } & \multirow[t]{3}{*}{$<0.001$} & {$[1]$} & 57 & & \\
\hline & & {$[2]$} & 71 & 1.86 & $1.16-2.98$ \\
\hline & & {$[3]$} & 82 & 1.82 & $1.07-3.08$ \\
\hline
\end{tabular}$$
1.93 \quad 0.72-5.21
$$

\begin{tabular}{|c|c|c|c|c|c|}
\hline \multirow{3}{*}{ C. jac } & \multirow{3}{*}{0.041} & [1] & 39 & 0.70 & $0.27-1.83$ \\
\hline & & {$[0]$} & 31 & & \\
\hline & & [1] & 53 & 2.51 & $1.13-5.60$ \\
\hline
\end{tabular}

\begin{tabular}{lccccc}
\hline \multicolumn{2}{ll}{ Cis bidentatus $(\mathrm{n}=92)$} & & & & \\
\hline Var. & $\mathrm{p}$-value & Cat. & Perc. & O.R. & $95 \%$-CI \\
\hline B. ret & 0.467 & {$[0]$} & 47 & &
\end{tabular}

\begin{tabular}{|c|c|c|c|c|c|}
\hline & & [1] & 56 & 1.68 & $0.56-4.97$ \\
\hline \multirow[t]{4}{*}{ Degr } & 0.419 & [1] & 25 & & \\
\hline & & [2] & 46 & 2.55 & $0.60-10.96$ \\
\hline & & [3] & 50 & 1.18 & $0.47-2.95$ \\
\hline & & [4] & 57 & 1.33 & $0.26-6.83$ \\
\hline
\end{tabular}

D. dre $\quad 0.350 \quad[0] \quad 43$

\begin{tabular}{llllll} 
& & {$[4]$} & 57 & 1.33 & $0.26-6.83$ \\
E. cor & 0.931 & {$[0]$} & 45 & & \\
\multirow{3}{*}{ Hag } & \multirow{2}{*}{0.613} & {$[1]$} & 46 & 1.05 & $0.35-3.18$ \\
& & {$[1]$} & 43 & & \\
Mois & \multirow{2}{*}{0.043} & {$[2]$} & 49 & 1.24 & $0.54-2.84$ \\
& & {$[1]$} & 59 & & \\
& & {$[3]$} & 40 & 0.45 & $0.19-1.10$ \\
Vol & 0.338 & {$[1]$} & 40 & & $0.07-1.97$ \\
& & {$[2]$} & 58 & 2.02 & $0.79-5.17$ \\
& & {$[3]$} & 44 & 0.59 & $0.13-2.70$ \\
\hline
\end{tabular}

Cis lineatocribratus $(\mathrm{n}=167)$

\begin{tabular}{cccccc}
\hline Var. & p-value & Cat. & Perc. & O.R. & $95 \%$-CI \\
\hline B.ret & 0.128 & {$[0]$} & 19 & & \\
& & {$[1]$} & 11 & 0.47 & $0.17-1.32$ \\
C. jac & 0.614 & {$[0]$} & 14 & & \\
& & {$[1]$} & 18 & 1.28 & $0.48-3.41$ \\
D. dre & 0.544 & {$[0]$} & 16 & & \\
& & {$[1]$} & 25 & 1.71 & $0.33-8.92$ \\
\hline
\end{tabular}

TABLE 5 (continued).

Cis lineatocribratus $(\mathrm{n}=167)$

\begin{tabular}{cccccc}
\hline Var. & p-value & Cat. & Perc. & O.R. & $95 \%$-CI \\
\hline Degr & 0.175 & {$[1]$} & 17 & & \\
& & {$[2]$} & 23 & 1.44 & $0.48-4.41$ \\
& & {$[3]$} & 12 & 0.44 & $0.16-1.22$ \\
& & {$[4]$} & 6 & 0.44 & $0.05-3.94$ \\
E. cor & 0.783 & {$[0]$} & 17 & & \\
& & {$[1]$} & 20 & 1.26 & $0.25-6.27$ \\
Hag & 0.380 & {$[1]$} & 17 & & \\
& & {$[2]$} & 8 & 0.43 & $0.05-3.48$ \\
Mois & 0.014 & {$[1]$} & 7 & & \\
& & {$[2]$} & 15 & 2.51 & $0.65-9.70$ \\
& & {$[3]$} & 28 & 2.19 & $0.89-5.38$ \\
Vol & 0.506 & {$[1]$} & 14 & & \\
& & {$[2]$} & 18 & 1.33 & $0.51-3.46$ \\
& & {$[3]$} & 24 & 1.42 & $0.43-4.70$
\end{tabular}

\begin{tabular}{cccccc}
\hline \multicolumn{6}{l}{ Ennearthron cornutum $(\mathrm{n}=312)$} \\
\hline Var. & p-value & Cat. & Perc. & O.R. & $95 \%$-CI \\
\hline
\end{tabular}

$\begin{array}{cccccc} & & & & & \\ \text { B. ret } & 0.627 & {[0]} & 16 & & \\ & & {[1]} & 18 & 1.17 & 0.62-2.22\end{array}$

C. bid $\quad 0.517-[0]$

$\begin{array}{cccccc} & & {[1]} & 18 & 1.18 & 0.49-2.85 \\ \text { C. } \operatorname{lin} \quad 0.716 & {[0]} & 17 & & \end{array}$

$\begin{array}{llllll}\text { C. } \text { lin } & 0.716 & {[0]} & 17 & & \\ & & {[1]} & 11 & 0.63 & 0.14-2.81 \\ \text { C. jac } & 0.445 & {[0]} & 19 & & \end{array}$

$\left[\begin{array}{lllll}{[1]} & 15 & 0.78 & 0.41-1.48\end{array}\right.$

D. dre $\quad 0.001 \quad[0] \quad 14$

$\begin{array}{lllll}{[1]} & 41 & 4.21 & 1.82-9.73\end{array}$

$\begin{array}{lrrrrr}\text { Degr } & 0.004 & {[1]} & 6 & & \\ & & {[2]} & 13 & 2.25 & 0.63-7.97\end{array}$

[3] $27 \quad 2.41 \quad 1.25-4.64$

\begin{tabular}{|c|c|c|c|c|}
\hline \multirow{2}{*}{ Hag } & \multirow[t]{2}{*}{$<0.001$} & [1] & 9 & \\
\hline & & [2] & 41 & 6.86 \\
\hline
\end{tabular}

$\begin{array}{llll}{[4]} & 9 & 0.27 & 0.06-1.24\end{array}$

Mois $<0.001 \quad[1] \quad 35$

$0.24 \quad 0.12-0.48$

$\begin{array}{llll}{[2]} & 11 & 0.24 & 0.12-0.48 \\ {[3]} & 10 & 0.81 & 0.34-1.90\end{array}$

Vol $\quad 0.491 \quad[1] \quad 15$

$1.41 \quad 0.72-2.75$

\begin{tabular}{llll}
{$[2]$} & 20 & 1.41 & $0.72-2.75$ \\
{$[3]$} & 14 & 0.62 & $0.25-1.53$ \\
\hline
\end{tabular}

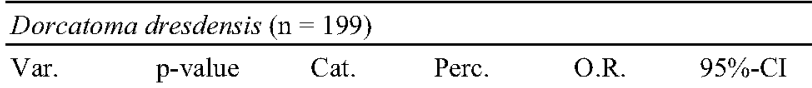

\begin{tabular}{lccccc}
\hline Var. & p-value & Cat. & Perc. & O.R. & $95 \%$-CI \\
\hline B. ret & 0.093 & {$[0]$} & 22 & & \\
& & {$[1]$} & 12 & 0.49 & $0.20-1.18$
\end{tabular}

$\begin{array}{llllll}\text { C. bid } & 0.085 & {[0]} & 17 & & \\ & & {[1]} & 31 & 2.23 & 0.92-21.56\end{array}$

$\begin{array}{lll}\text { C. } \operatorname{lin} & 0.842 & {[0]}\end{array}$

$\begin{array}{llllll}\text { C. jac } & & {[1]} & 17 & 0.85 & 0.18-4.06 \\ & 0.888 & {[0]} & 18 & & \\ & & {[1]} & 19 & 1.06 & 0.48-2.35\end{array}$

E. cor $<0.001$

\begin{tabular}{|c|c|c|c|c|c|}
\hline \multirow[t]{2}{*}{ Hag } & \multirow[t]{2}{*}{$<0.001$} & [1] & 12 & & \\
\hline & & [2] & 39 & 4.47 & $2.11-9.45$ \\
\hline
\end{tabular}

$\begin{array}{lllll} & {[1]} & 58 & 7.94 & 2.93-21.56\end{array}$

Mois $\quad 0.012 \quad[1] \quad 32$

$\begin{array}{llll}{[1]} & 32 & & \\ {[2]} & 18 & 0.47 & 0.21-1.05\end{array}$

\begin{tabular}{|c|c|c|c|c|c|}
\hline Vol & 0.056 & {$[1]$} & 11 & & \\
\hline & & [2] & 20 & 1.99 & $0.76-5.24$ \\
\hline & & [3] & 26 & 1.47 & $0.64-3.37$ \\
\hline
\end{tabular}

[3] $\quad 9 \quad 0.44 \quad 0.15-1.26$ 
TABLE 6. Spearman rank correlation between pairs of variables for each species of beetle. Only correlations with Spearman Rho $<-0.30$ and $>0.30$ are included in the table $(\mathrm{n}=$ $463,92,167,312$ and 199)

\begin{tabular}{lccrrr}
\hline Species & $\begin{array}{c}\text { Variable } \\
\text { against }\end{array}$ & $\begin{array}{l}\text { Vari- } \\
\text { able }\end{array}$ & $\begin{array}{r}\text { Spearman } \\
\text { Rho }\end{array}$ & p-value \\
\hline Cis jacquemartilalter & Mois & Hag & -0.395 & $<0.001$ \\
Cis bidentatus & Mois & Hag & -0.300 & 0.005 \\
Cis bidentatus & Vol & C. jac & 0.360 & $<0.001$ \\
Cis bidentatus & Vol & B. ret & 0.407 & $<0.001$ \\
Cis lineatocribratus & Mois & Hag & -0.367 & $<0.001$ \\
Ennearthron cormutum & Mois & Hag & -0.416 & $<0.001$ \\
Ennearthron cornutum & Hag & C. jac & -0.320 & $<0.001$ \\
Dorcatoma dresdensis & Mois & Hag & -0.485 & $<0.001$ \\
Dorcatoma dresdensis & Hag & C. jac & -0.318 & $<0.001$ \\
Dorcatoma dresdensis & Hag & E. cor & 0.355 & $<0.001$ \\
\hline
\end{tabular}

interspecific competition in moist basidiocarps. It is also possible that $C$. lineatocribratus may be less resistant to desiccation forcing them to live in more moist basidiocarps.

\section{Interspecific interactions}

Presence of $C$. bidentatus in basidiocarps was positively associated with the presence of $C$. jacquemarti/alter, and that of $E$. cornutum with $D$. dresdensis. In contrast, $D$. dresdensis was negatively associated with the presence of $B$. reticulatus, and $C$. lineatocribratus with $C$. bidentatus. Through their tunnelling, major fungivorous beetles can provide easier access to the interior of $F$. fomentarius basidiocarps for other species (Matthewman \& Pielou, 1971). Thus, presence of the numerous C. jacquemarti/alter and $D$. dresdensis may improve habitat conditions for $C$. bidentatus and $E$. cornutum. In addition, resource competition is common between fungivorous insects (Hanski, 1989), and important competitors in dead wood fungi in North America are Tenebrionidae (like B. reticulatus) and Anobiidae (like D. dresdensis) (Lawrence, 1973). Therefore, B. reticulatus may be a superior competitor to the smaller $D$. dresdensis.

\section{Degradation of basidiocarps}

The successional stage of a basidiocarp is an important factor determining the presence of beetles inhabiting basidiocarps of dead wood fungi (Midtgaard et al., 1998; Jonsell et al., 1999). In this study percentage degradation, which indicates the amount of resources removed from the basidiocarps, was used as a measure of successional stage. One problem in assessing the importance of this variable was that some of the degradation categories had low numbers of observation (Fig. 3). This reduces the likelihood of discovering real effects of successional degradation. Trends were, however, noticeable for $C$. jacquemarti/alter, E. cornutum and D. dresdensis. Since $C$. jacquemarti/alter and $D$. dresdensis probably substantially contribute to the degradation process, it is not surprising that they are less frequently present in minimally degraded $(<1 \%)$ than in highly degraded basidiocarps.
The peak of presence of E. cornutum occurs somewhat later in the succession than the other two species, and it may need other species to modify the microhabitat conditions inside the basidiocarps before it can utilise this resource. Jonsell et al. (1999) using another measurement of basidiocarp succession, showed that $E$. cornutum entered dead basidiocarps rather late in the succession. Observing that only $E$. cornutum had a distinct drop in incidence among the most degraded basidiocarps may be a result of this last category being too wide ranging (50-100\% degradation) and coarse to indicate lack of resources for most species.

\section{CONCLUSION}

The present study shows how beetle species inhabiting $F$. fomentarius basidiocarps differ in their microhabitat requirements. This indicates that basidiocarps of just one species, $F$. fomentarius, are a heterogeneous resource varying at a local scale. Earlier, the importance of largescale variables for the presence of the same species on basidiocarp trees has been documented (Rukke, 2000). Together these results have important implications for the conservation of these beetles. There is a need to consider both the landscape ecological and microhabitat aspects in order to better assess and counteract the consequences of human activities. A conservation strategy of leaving behind sufficient amount of this heterogeneous resource within a certain degree of isolation is needed to preserve these and possibly other species of beetles inhabiting basidiocarps of dead wood fungi. In other words, providing plentiful dead wood and their associated basidiocarps in forests is essential because only this will ensure a proper supply of basidiocarps of different quality within the dispersal range of these beetles.

ACKNOWLEDGEMENTS. I would like to thank Rolf A. Ims, Fred Midtgaard, Nina Alstad Rukke and Anne SverdrupThygeson for valuable comments on an earlier version of the manuscript. Sindre Ligaard is thanked for classifying the beetles.

\section{REFERENCES}

Bader P., Jansson S. \& Jonsson B.G. 1995: Wood-inhabiting fungi and substratum decline in selectively logged boreal spruce forests. Biol. Conserv. 72: 355-362.

DiAMOND J.M. 1984: Normal extinctions of isolated populations. In Nitecki M.H. (ed.): Extinctions. The University of Chicago Press, Chicago, pp. 191-246.

Esseen P.-A., Ehnström B., Ericson L. \& Siöberg K. 1997: Boreal Forest. Ecol. Bull. 46: 16-47.

Fossli T.E. \& ANDERSEN J. 1998: Host preference of Cisidae (Coleoptera) on tree-inhabiting fungi in northern Norway. Entomol. Fennica 9: 65-78.

GehrKen U., Stromme A., Lundheim R. \& Zachariassen K.E. 1991: Inoculative freezing in overwintering Tenebrionid beetle, Bolitophagus reticulatus Pantz. J. Insect Physiol. 37: 683-687.

Haila Y., Hanski I.K., Niemelä J., Punttila P., Raivio S. \& TuKIA H. 1994: Forestry and the boreal fauna: Matching management with natural forest dynamics. Ann. Zool. Fennici 31: 187-202. 
HANSKI I. 1989: Fungivory: Fungi, insects and ecology. In: Wilding N., Collins N.M., Hammond P.M. \& Webber J.F. (eds): Insect-Fungus Interactions. Academic Press, London, pp. 25-68.

Harmon M.E., Franklin J.F., Swanson F.J., Sollins P., Gregory S.V., Lattin J.D., Anderson N.H., Cline S.P., Aumen N.G., Sedell J.R., Lienkaemper G.W., Cromack JR. K. \& Cummins K.W. 1986: Ecology of coarse woody debris in temperate ecosystems. In: MacFayden A. \& Ford E.D. (eds): Advances in Ecological Research. Academic Press, New York, pp. 133-302.

Hosmer JR. D.W. \& Lemeshow S. 1989: Applied Logistic Regression. John Wiley \& Sons, New York, 307 pp.

Jonsell M. \& NoRDLANDER G. 1995: Field attraction of Coleoptera to odours of the wood-decaying polypores Fomitopsis pinicola and Fomes fomentarius. Ann. Zool. Fennici 32: 391-402.

Jonsell M. 1999: Insects on Wood-Decaying Polypores: Conservation Aspects. Ph.D. thesis, Swedish University of Agricultural Sciences, Uppsala.

Jonsell M., Nordlander G. \& Ehnström B. 1999: Substrate preferences of insects breeding in wood-decaying fungi. In: Ph.D. thesis by Jonsell M.: Insects on Wood-Decaying Polypores: Conservation Aspects. Swedish University of Agricultural Sciences, Uppsala, pp. 1-39.

Kaila L., Martikainen P., Punttila P. \& Yakovlev E. 1994: Saproxylic beetles (Coleoptera) on dead birch trunks decayed by different polypore species. Ann. Zool. Fennici 31: 97-107.

KINDVALl O. \& AHLÉN I. 1992: Geometrical factors and metapopulation dynamics of the bush cricket, Metrioptera bicolor Philippi (Orthoptera: Tettiogoniidae). Cons. Biol. 6: 520-529.

Knutsen H., Rukke B.A., Jorde P.E. \& Ims R.A. 2000: Genetic differentiation among populations of the beetle Bolitophagus reticulatus (Coleoptera: Tenebrionidae) in a fragmented and a continuous landscape. Heredity 84: 667-676

LAWRENCE J.F. 1973: Host preference in ciid beetles (Coleoptera: Ciidae) inhabiting the fruiting bodies of basidiomycetes in North America. Bull. Mus. Comp. Zool. 145: 163-212.

Lindroth C.H. (ed.) 1960: Catalogus Coleopterorum Fennoscandiae et Daniae. Entomologiska Sällskapet, Lund, 476 pp.

Lucht W.H. 1987: Die Käfer Mitteleuropas. Katalog. Goecke und Evers Verlag, Krefeld, 342 pp.
Matthewman W.G. \& Pielou D.P. 1971: Arthropods inhabiting the sporophores of Fomes fomentarius (Polyporaceae) in Gatineau Park, Quebec. Can. Entomol. 103: 775-847.

MidtgaARd F., Rukke B.A. \& Sverdrup-Thygeson A. 1998: Habitat use of the fungivorous beetle Bolitophagus reticulatus (Coleoptera: Tenebrionidae): Effects of basidiocarp size, humidity and competitors. Eur. J. Entomol. 95: 559-570.

Nicsson T. 1997: Spatial population dynamics of the black tinder fungus beetle Bolitophagus reticulatus (Coleoptera: Tenebrionidae). Comprehensive Summaries of Uppsala Diss. from the Fac. of Sci. and Technol. 311: 1-44.

ØKLAND B. 1995: Insect fauna compared between six polypore species in a southern Norwegian spruce forest. Fauna Norv. Ser. B. 42: 21-26.

PAviour-Smith K. 1960: The fruiting-bodies of macrofungi as habitats for beetles of the family Ciidae (Coleoptera). Oikos 11: 43-71.

RuKKE B.A. 2000: Effects of habitat fragmentation: Increased isolation and reduced habitat size reduces the incidence of dead wood fungi beetles in a fragmented forest landscape. Ecography 23: 492-502.

RUKKE B.A. \& MidTGAaRD F. 1998: The importance of scale and spatial variables for the fungivorous beetle Bolitophagus reticulatus (Coleoptera: Tenebrionidae) in a fragmented forest landscape. Ecography 21: 561-572.

SAS InSTiTuTE INC. 1997: JMP. vers 3.2.2. Cary, North Carolina. Soulé M.E. (ed.) 1986: Conservation Biology: The Science of Scarcity and Diversity. Sinauer Associates Inc., Sunderland, $584 \mathrm{pp}$.

SVerdrup-Thygeson A. \& Midtgaard F. 1998: Fungus infected trees as islands in boreal forest: Spatial distribution of the fungivorous beetle Bolitophagus reticulatus (Coleoptera: Tenebrionidae). Ecoscience 5: 486-493.

Thunes K.H. 1994: The coleopteran fauna of Piptoporus betulinus and Fomes fomentarius (Aphyllophorales: Polyporaceae) in western Norway. Entomol. Fennica 5: 157-168.

VIK A. 1991: Catalogus Coleopterorum Norvegica. [Norwegian catalogue of Coleoptera] Stig Otto Hansen, Larvik, 157 pp. (in Norwegian).

WIENS J.A. 1976: Population responses to patchy environments. Annu. Rev. Ecol. Syst. 7: 81-120.

Williamson M. 1981: Island Populations. Oxford University Press, Oxford, $281 \mathrm{pp}$.

Received June 23, 2000; revised March 22, 2001; accepted December 11, 2001 